\section{Prevalência e fatores associados às manifestações bucais em pacientes HIV positivos atendidos em cidade sul-brasileira}

\author{
Prevalence of oral lesions in persons with HIV and \\ associated factors in a southern Brazilian city
}

\author{
${ }_{1}$ Universidade Federal do Rio \\ Grande, Rio Grande, Brasil. \\ 2 Programa de Pós-graduação \\ em Ciências Odontológicas, \\ Universidade Federal de \\ Santa Maria, Santa Maria \\ Brasil. \\ 3 Centro de Ciências da \\ Saúde, Universidade Federal \\ de Santa Maria, Santa Maria, \\ Brasil. \\ Correspondência \\ F. V. Ferreira \\ Programa de Pós-graduação \\ em Ciências Odontológicas, \\ Universidade de Santa Maria \\ Rua Visconde de Pelotas 517 \\ Santa Maria, RS \\ 97010-440, Brasil. \\ fabivfer@yahoo.com.br
}

\begin{abstract}
The aim of the study was to assess the prevalence of oral lesions in AIDS patients and identify associated factors. A cross-sectional study collected data from interviews, clinical examination, and a review of medical records for adult patients treated at the HIVIAIDS clinic in the University Hospital of the Federal University in Rio Grande, Rio Grande do Sul State, Brazil, focusing on socio-demographic, immune status, and treatment factors. Poisson regression was used in a hierarchical analytical model. From April 2006 to January 2007, 300 patients were observed (51\% males; mean age 40 years). Of the total, $39 \%$ presented oral lesions, with candidiasis as the most frequent (59.1\%), followed by hairy leukoplakia (19.5\%). Women showed a lower risk of oral lesions, and there was an inverse association with CD4 count. Increased risk was associated with lower schooling, low income, smoking, alcohol addiction, time since HIV seroconversion, and higher viral load. The data confirm the increased prevalence of opportunistic oral lesions and show their relationship to socioeconomic conditions and modifiable habits and customs.
\end{abstract}

Oral Manifestations; Oral Health; HIV
Adriano Baraciol Gasparin 1

Fabiana Vargas Ferreira ${ }^{2}$

Cristiane Cademartori Danesi 3

Raúl Andrés Mendoza-Sassi 1

Jussara Silveira 1

Ana Maria Barral Martinez 1

Linjie Zhang 1

Juraci A. Cesar 1

\section{Introdução}

As lesões bucais estão fortemente associadas à infecção pelo HIV. A principal característica patológica do vírus da imunodeficiência humana é a diminuição progressiva da imunidade celular e o conseqüente aparecimento de infecções oportunistas e neoplasias malignas ${ }^{1}$. A infecção compromete o sistema imune de maneira sistêmica, o que ocasiona também depleção na função imunológica da mucosa bucal, tornando-a suscetível a diversas alterações 2,3, tais como: candidíase, leucoplasia pilosa, sarcoma de Kaposi, linfoma não-Hodgkin, gengivite ulcerativa necrotizante aguda e periodontite 3

As manifestações bucais da infecção pelo HIV são comuns e podem representar um importante valor diagnóstico da doença 4,5. Aproximadamente $60 \%$ dos indivíduos infectados pelo HIV e $80 \%$ daqueles com AIDS apresentam essas manifestações 3,6. Portanto, a presença de alterações bucais "oportunistas" sugestivas de um estado de imunodepressão deve induzir a buscar no paciente a possibilidade de infecção pelo HIV, ou alertar para uma queda imunológica naqueles que tem a doença 1 .

Em pacientes HIV positivos, alguns fatores podem contribuir para o desenvolvimento precoce dessas lesões: linfócitos T-CD4 abaixo de 200 células $/ \mathrm{mm}^{3}$, carga viral elevada, xerostomia, higiene bucal precária e uso de tabaco 1,6. Com o início da terapia anti-retroviral (TARV) 
combinada, alguns pesquisadores verificaram a redução acentuada na ocorrência de infecções oportunistas e na prevalência das manifestações bucais 7,8 . Isso ocorre devido à recuperação parcial da função imunológica após supressão da viremia, redução da destruição celular causada pelo HIV e possivelmente ao efeito antiapoptose de algumas drogas 9,10 .

A terapia anti-retroviral diminui a carga viral do HIV e aumenta as células CD4+, resultando em menor freqüência de lesões oportunistas 7 . Quando estas aparecem na vigência de tratamento, podem indicar falha terapêutica 4 .

Tendo em vista tais aspectos, o presente trabalho teve como objetivo estudar a prevalência de lesões bucais entre pacientes HIV positivos, assim como analisar os fatores associados à sua ocorrência, permitindo, assim, traçar um perfil epidemiológico dos pacientes assistidos em cidade sul-brasileira.

\section{Material e métodos}

Realizou-se um estudo observacional, analítico, de tipo transversal. Fizeram parte da amostra, pacientes atendidos no serviço de HIV/AIDS do Hospital Universitário da Universidade Federal do Rio Grande, em Rio Grande, Rio Grande do Sul, Brasil. Para cálculo da amostra foram utilizados diversos fatores de risco. O cálculo que exigiu um " $n$ " maior teve os seguintes parâmetros: erro alfa de 0,05 , poder de $80 \%$, prevalência para lesões bucais de $30 \%$, uma relação de não expostos para expostos de 4:1 (fator de exposição contagem de CD4 igual ou menor a 200 células $/ \mathrm{mm}^{3}$ ), uma prevalência de lesão bucal nos não expostos de $25 \%$ e um risco relativo de 2 . Com esses parâmetros, seriam necessários 195 pacientes. Acrescido de $10 \%$ para perdas e $40 \%$ para análise de fatores de confusão, chegou-se a um $n$ de 293 pacientes a serem examinados. Para a coleta de dados, foi utilizada a observação clínica, um questionário específico e dados secundários existentes nos prontuários dos pacientes. Os dados foram coletados por um pesquisador (A.B.G.), que foi previamente treinado para o diagnóstico das lesões bucais (kappa $=0,61-0,82$ ). O período de coleta iniciou no mês de abril de 2006 e se estendeu até janeiro de 2007. Todos os pacientes que eram atendidos no dia da sua consulta no serviço ou se encontravam internados, eram entrevistados consecutivamente. Após apresentação e prévia concordância de participação, leitura e assinatura do termo de consentimento, aplicou-se um questionário e realizou-se exame bucal.

As lesões bucais de interesse foram leucoplasia pilosa, candidíase da mucosa bucal, queilite, herpes, úlcera da mucosa e sarcoma de Kaposi. As variáveis sócio-demográficas estudadas foram: faixa etária em anos, sexo, escolaridade em anos completos, estado civil (companheiro) e renda familiar per capita. Nas variáveis relacionadas a hábitos e costumes, foram estudados o hábito de escovar os dentes, o fumo, o uso de álcool e a dependência ao álcool avaliado pelo questionário CAGE (ponto de corte $0 / 1$ ). Nas variáveis clínico-laboratoriais, incluíram-se a forma de transmissão - classificada como heterossexual, homossexual ou bissexual -; uso de drogas injetáveis e transfusional; tempo de evolução desde o diagnóstico de HIV; carga viral inicial; contagem de linfócitos T CD4 inicial; contagem de linfócitos CD4 e carga viral no diagnóstico da lesão bucal; se estava em uso de anti-retrovirais (ARV) e se o paciente estava internado. Os dados referentes ao tempo de evolução da infecção pelo HIV e os dados laboratoriais foram extraídos dos prontuários. Para a contagem de linfócitos T CD4 e carga viral do momento do exame da cavidade bucal, foram utilizados os valores de linfócitos T CD4 e de carga viral referentes ao período mais próximo da entrevista, e nenhum período foi maior que três meses.

Os dados foram digitados no programa Epi Info 6.04 (Centers for Disease Control and Prevention, Atlanta, Estados Unidos) em duas oportunidades de forma independente. Posteriormente, realizou-se a comparação dos dois bancos para identificar e corrigir erros de digitação. Após, foi realizada a limpeza do banco final procurando-se possíveis erros de amplitude ou de consistência. A seguir, o banco foi exportado para o programa Stata 9.0 (Stata Corp., College Station, Estados Unidos) onde foram feitas as análises. $\mathrm{Na}$ análise estatística, foi realizada em primeiro lugar a descrição da amostra estudada mediante o cálculo das prevalências e das médias e desvios padrões das diferentes variáveis. Em continuidade, realizou-se a análise bivariada, pela qual foram estudadas as associações entre os diversos fatores e o desfecho definido como presença ou ausência de lesão bucal. Calcularam-se as razões de prevalência (RP) e os intervalos de $95 \%$ de confiança (IC95\%). Na análise multivariada, foi utilizada a regressão de Poisson, com variância robusta. A regressão foi de tipo para trás e seguiu um modelo hierárquico de análise composto por três níveis. O primeiro nível incluía todas as variáveis sócio-demográficas; o segundo nível, as variáveis relacionadas a hábitos e costumes. No terceiro nível estavam contempladas as variáveis referentes aos aspectos clínicos e laboratoriais. Em cada nível foram incluídas todas as variáveis. Aquelas com um valor de $\mathrm{p}$ igual ou inferior a 0,20 eram mantidas para ajuste com as variáveis 
do nível seguinte, a fim de considerar a possibilidade de confusão negativa. Em cada nível e para cada variável, calcularam-se as RP e seus respectivos IC95\%. O teste estatístico utilizado foi o teste de Wald. No caso de variáveis categóricas ordenadas, foi realizado o teste de Wald para tendência linear. Já para variáveis categóricas não ordenadas foi realizado um teste de heterogeneidade. Em todos os casos utilizou-se um ponto de corte para o valor de p menor a 0,05 de um teste bicaudal.

A pesquisa foi aprovada pelo Comitê de Ética da Área da Saúde da Universidade Federal do Rio Grande (processo 23116.6649/5.5 parecer no ${ }^{\circ}$. 012/2006), estando em acordo com o código de ética relacionado a seres humanos.

\section{Resultados}

Durante o período do estudo, foram entrevistados 306 pacientes. Desses, $2 \%(n=6)$ recusaramse a participar da pesquisa. Não houve perdas de informação diferencial com relação às variáveis obtidas dos prontuários (contagem de linfócitos T CD4, carga viral), uma vez que os dados dos prontuários estavam disponíveis para todos os participantes. As características da amostra estão representadas na Tabela 1. A média de idade ficou em 39,38 anos (desvio-padrão - DP = 12,34). Dos aspectos referentes às condições sócio-econômicas da amostra, $12,7 \%$ dos pacientes não sabiam ler ou escrever, e somente $35 \%$ tinham oito ou mais anos de estudo. A renda familiar per capita teve uma média de $\mathrm{R} \$ 208,49(\mathrm{DP}=247,41)$. Em alusão aos hábitos e costumes, o uso de tabaco foi declarado por $51,3 \%$ da amostra, sendo a média de cigarros fumados por dia de 7,88, com um mínimo de 2 e máximo de 60 cigarros. O uso de álcool foi citado por $37 \%$ da amostra e a dependência ao álcool foi verificada em $26,3 \%$ dos indivíduos. A maioria dos pacientes era heterossexual (75\%) e apenas 0,6\% tiveram a forma de transmissão por transfusão sangüínea. Quanto ao tempo de diagnóstico pelo HIV, o tempo mínimo foi de 2 meses, o máximo de 14,4 anos e a média de 4,6 anos ( $\mathrm{DP}=3,12)$. Dois terços dos pacientes estavam em uso de drogas anti-retrovirais. O valor médio da contagem de linfócitos T CD4 no momento do exame da cavidade bucal foi de 440 células $/ \mathrm{mm}^{3}$ ( $\mathrm{DP}=272,70$ ), enquanto a carga viral se situou em 2,34 log ( $\mathrm{DP}=2,05)$. Já os valores encontrados no momento do diagnóstico do HIV foram 305,56 células $/ \mathrm{mm}^{3}(\mathrm{DP}=246)$ e carga viral de 4,01 $\log (\mathrm{DP}=1,43)$. Dos 300 pacientes, 39\% (IC95\%: 33,4-44,6) apresentavam alguma manifestação estomatológica. As manifestações mais prevalentes foram candidíase, sendo $59,1 \%$ localizadas na cavidade bucal e 10,7\% eram na forma de queilite angular. A leucoplasia pilosa situou-se em segundo lugar $(25,2 \%)$, seguida do herpes $(5,7 \%)$ e das úlceras (5\%). Não houve nenhuma lesão de sarcoma de Kaposi.

Na Tabela 2, pode ser observada a análise bivariada e as razões de prevalência brutas. As variáveis significativas $(\mathrm{p}<0,05)$ foram a baixa escolaridade, renda per capita, tabagismo, desordens por uso de álcool (CAGE), higiene oral (escovar os dentes), tempo de diagnóstico, uso de drogas injetáveis, estar internado, linfócitos T CD4 no diagnóstico e carga viral no exame.

A análise multivariada está representada na Tabela 3, em que podem ser vistas as razões de prevalência ajustadas: no primeiro nível, após ajuste entre os fatores sócio-demográficos, permaneceram no modelo sexo, escolaridade e renda. Quanto ao sexo, as mulheres apresentaram uma probabilidade $27 \%$ menor de ter lesão oral. Já com respeito à escolaridade, houve um aumento do risco no grupo de 4-7 $(\mathrm{RP}=1,51)$. Com referência à renda, cada aumento de um real determinou uma redução de dois por mil na probabilidade de ter lesão bucal.

No segundo nível e ajustado para as variáveis que permaneceram no modelo do primeiro nível, foram significativos o número de cigarros fumados e a dependência ao álcool (CAGE). Cada cigarro a mais fumado determinou um aumento na probabilidade de ter lesão bucal de $2 \%$. Já aqueles que tiveram um CAGE positivo mostraram um aumento do risco para o desfecho de $143 \%$. O tempo de duração do hábito de fumar e a variável hábito de escovar os dentes foram retiradas do modelo, visto que, ajustadas, apresentaram um valor de p maior a 0,20 . No último nível, após ajuste com as outras variáveis, incluindo valores de linfócitos T CD4, carga viral e uso de ARV, o tempo de evolução da doença apresentou uma associação significativa com o desfecho. Assim, cada ano de doença aumentou a probabilidade de ter lesão bucal em 7\%. A contagem de linfócitos T CD4 no momento do diagnóstico da doença continuou sendo significativa na análise multivariada. Cada incremento em uma célula $/ \mathrm{mm}^{3}$ produziu uma queda na probabilidade do desfecho de um por mil. Cada incremento de um $\log$ na carga viral no momento do estudo fez com que a probabilidade de lesão bucal aumentasse em $12 \%$. Os pacientes internados tiveram um aumento de $79 \%$ na probabilidade de apresentar algum tipo de lesão oral. As variáveis grupo de transmissão, linfócitos T CD4 no exame e a carga viral no momento do diagnóstico do HIV após o ajuste não apresentaram significância. Os pacientes em uso de ARV tiveram uma redução do risco, mas o valor de p não foi significante. 
Tabela 1

Características da amostra estudada. Serviço HIV-AIDS, Hospital Universitário da Universidade Federal do Rio Grande, em Rio Grande, Rio Grande do Sul, Brasil, 2006 ( $N=300)$.

\begin{tabular}{|c|c|c|}
\hline Variáveis & $\mathbf{n}$ & $\%$ \\
\hline \multicolumn{3}{|l|}{ Origem do paciente } \\
\hline Ambulatorial & 270 & 90,0 \\
\hline Internado & 30 & 10,0 \\
\hline \multicolumn{3}{|l|}{ Sexo } \\
\hline Masculino & 153 & 51,0 \\
\hline Feminino & 147 & 49,0 \\
\hline \multicolumn{3}{|l|}{ Faixa etária (anos) } \\
\hline $15-29$ & 84 & 28,0 \\
\hline $30-44$ & 124 & 41,3 \\
\hline $45-59$ & 72 & 24,0 \\
\hline 60 ou mais & 20 & 6,7 \\
\hline \multicolumn{3}{|l|}{ Cor } \\
\hline Branco & 246 & 82,0 \\
\hline Não branco & 54 & 18,0 \\
\hline \multicolumn{3}{|l|}{ Estado civil } \\
\hline Com companheiro & 150 & 50,0 \\
\hline Sem companheiro & 150 & 50,0 \\
\hline \multicolumn{3}{|l|}{ Alfabetizado } \\
\hline Sim & 262 & 87,3 \\
\hline Não & 38 & 12,7 \\
\hline \multicolumn{3}{|l|}{ Tempo de estudo (anos) } \\
\hline $0-3$ & 77 & 25,7 \\
\hline $4-7$ & 118 & 39,3 \\
\hline 8 ou mais & 105 & 35,0 \\
\hline \multicolumn{3}{|l|}{ Trabalho } \\
\hline Sim & 109 & 36,3 \\
\hline Não & 191 & 63,7 \\
\hline \multicolumn{3}{|l|}{ Fumo } \\
\hline Nunca fumou & 90 & 30,0 \\
\hline Ex-fumante (1 ano) & 56 & 18,7 \\
\hline Fumante & 154 & 51,3 \\
\hline \multicolumn{3}{|l|}{ Escovar os dentes } \\
\hline Sim & 293 & 98,3 \\
\hline Não & 5 & 1,7 \\
\hline \multicolumn{3}{|l|}{ Uso de álcool } \\
\hline Sim & 111 & 37,0 \\
\hline Não & 189 & 63,0 \\
\hline Uso de anti-retrovirais & 200 & 66,7 \\
\hline \multicolumn{3}{|l|}{ Grupo de transmissão } \\
\hline Heterossexual & 225 & 75,0 \\
\hline Homo ou bissexual & 38 & 12,7 \\
\hline Uso de droga injetável & 35 & 11,7 \\
\hline Transfusão & 2 & 0,6 \\
\hline \multicolumn{3}{|l|}{ Presença de lesão } \\
\hline Sim & 117 & 39,0 \\
\hline \multirow[t]{2}{*}{ Não } & 183 & 61,0 \\
\hline & Média & DP \\
\hline Linfócitos T CD4 no diagnóstico (células/mm³) & 305,56 & 246,00 \\
\hline Linfócitos T CD4 no exame (células/mm³) & 440,00 & 272,70 \\
\hline Carga viral no diagnóstico (log) & 4,01 & 1,43 \\
\hline Carga viral no exame (log) & 2,34 & 2,05 \\
\hline
\end{tabular}


Razões de prevalência (RP) brutas para lesão bucal segundo fatores estudados. Serviço HIV-AIDS, Hospital Universitário da Universidade Federal do Rio Grande, em Rio Grande, Rio Grande do Sul, Brasil, 2006 (N = 300)

\begin{tabular}{|c|c|c|c|}
\hline Fatores & RP bruta & IC95\% & Valor de $p$ \\
\hline \multicolumn{4}{|l|}{ Faixa etária (anos) } \\
\hline 15- 29 & 1,00 & & 0,32 * \\
\hline $30-44$ & 1,12 & $0,78-1,62$ & \\
\hline $45-59$ & 1,36 & $0,93-2,01$ & \\
\hline 60 ou mais & 0,87 & $0,42-1,80$ & \\
\hline \multicolumn{4}{|l|}{ Cor } \\
\hline Branca & 1,00 & & 0,77 \\
\hline Não branca & 1,05 & $0,74-1,51$ & \\
\hline \multicolumn{4}{|l|}{ Sexo } \\
\hline Masculino & 1,00 & & 0,14 \\
\hline Feminino & 0,80 & $0,60-1,07$ & \\
\hline \multicolumn{4}{|l|}{ Companheiro (a) } \\
\hline Não & 1,00 & & 0,19 \\
\hline $\operatorname{Sim}$ & 1,21 & $0,90-1,60$ & \\
\hline \multicolumn{4}{|l|}{ Escolaridade (anos completos) } \\
\hline Menos de 4 & 1,00 & & 0,001 ** \\
\hline $4-7$ & 1,53 & $1,07-2,19$ & \\
\hline 8 ou mais & 0,85 & $0,54-1,31$ & \\
\hline Renda per capita familiar (R\$) & 0,998 & $0,998-0,999$ & 0,02 \\
\hline \multicolumn{4}{|l|}{ Fumo } \\
\hline Não & 1,00 & & 0,001 \\
\hline $\operatorname{Sim}$ & 1,48 & $1,22-1,81$ & \\
\hline Número de cigarros & 1,02 & $1,01-1,03$ & 0,001 \\
\hline Tempo de fumo (em anos) & 1,02 & $1,01-1,02$ & 0,001 \\
\hline \multicolumn{4}{|l|}{ Uso de álcool } \\
\hline Não & 1,00 & & 0,86 \\
\hline Sim & 1,03 & $0,76-1,37$ & \\
\hline \multicolumn{4}{|l|}{ CAGE } \\
\hline Negativo & 1,00 & & 0,02 \\
\hline Positivo & 1,40 & $1,05-1,86$ & \\
\hline \multicolumn{4}{|l|}{ Hábito de escovar os dentes } \\
\hline Em todas as refeições & 1,00 & & 0,002 * \\
\hline Em alguma refeição & 1,23 & $0,89-1,69$ & \\
\hline Em algum dia da semana & 1,91 & $1,34-2,74$ & \\
\hline Tempo de diagnóstico (anos) & 1,05 & $1,00-1,10$ & 0,02 \\
\hline \multicolumn{4}{|l|}{ Grupo de transmissão } \\
\hline Heterossexual/Transfusão & 1,00 & & $0,001 * \star$ \\
\hline Homo ou bissexual & 1,21 & $0,80-1,83$ & \\
\hline Uso de drogas injetáveis & 1,81 & $1,32-2,47$ & \\
\hline \multicolumn{4}{|l|}{ Uso de anti-retrovirais } \\
\hline Não & 1,00 & & 0,1 \\
\hline Sim & 0,80 & $0,60-1,06$ & \\
\hline \multicolumn{4}{|l|}{ Internação } \\
\hline Não & 1,00 & & 0,001 \\
\hline $\operatorname{Sim}$ & 2,45 & $1,94-3,08$ & \\
\hline Carga viral no diagnóstico & 1,04 & $0,93-1,15$ & 0,44 \\
\hline Linfócitos T CD4 no diagnóstico & 0,999 & $0,998-0,999$ & 0,02 \\
\hline Linfócitos T CD4 no exame & 0,999 & $0,999-1,000$ & 0,06 \\
\hline Carga viral no exame & 1,14 & $1,06-1,23$ & 0,001 \\
\hline
\end{tabular}

* Teste de tendência linear:

** Teste de heterogeneidade. 
Razões de prevalência (RP) ajustadas para lesão bucal segundo fatores estudados. Serviço HIV-AIDS, Hospital Universitário da Universidade Federal do Rio Grande, em Rio Grande, Rio Grande do Sul, Brasil, 2006 (N = 300).

\begin{tabular}{|c|c|c|c|}
\hline Níveis/Fatores & RP ajustada & IC95\% & Valor de $p$ \\
\hline \multicolumn{4}{|l|}{ 1o nível } \\
\hline \multicolumn{4}{|l|}{ Faixa etária (anos) } \\
\hline $15-29$ & 1,00 & & 0,3 ** \\
\hline $30-44$ & 1,10 & $0,77-1,57$ & \\
\hline $45-59$ & 1,31 & $0,89-1,94$ & \\
\hline 60 ou mais & 0,74 & $0,36-1,50$ & \\
\hline \multicolumn{4}{|l|}{ Cor } \\
\hline Branca & 1,00 & & 0,90 \\
\hline Não branca & 0,99 & $0,69-1,42$ & \\
\hline \multicolumn{4}{|l|}{ Sexo* } \\
\hline Masculino & 1,00 & & 0,03 \\
\hline Feminino & 0,73 & $0,54-0,97$ & \\
\hline \multicolumn{4}{|l|}{ Companheiro * } \\
\hline Não & & & 0,15 \\
\hline Sim & 1,23 & $0,93-1,63$ & \\
\hline \multicolumn{4}{|l|}{ Escolaridade (anos completos) * } \\
\hline Menos de 4 & 1,00 & & $0,02 * \star \star$ \\
\hline $4-7$ & 1,51 & $1,06-2,14$ & \\
\hline 8 ou mais & 0,98 & $0,64-1,50$ & \\
\hline Renda per capita familiar (R\$) * & 0,998 & $0,99-0,99$ & 0,006 \\
\hline \multicolumn{4}{|l|}{ 2oo nível } \\
\hline \multicolumn{4}{|l|}{ Fumo * } \\
\hline Não & & & 0,1 \\
\hline Sim & 1,18 & $0,94-1,48$ & \\
\hline Número de cigarros * & 1,02 & $1,01-1,03$ & 0,001 \\
\hline Tempo de fumo (anos) * & 1,02 & $0,99-1,01$ & 0,7 \\
\hline \multicolumn{4}{|l|}{ Uso de álcool * } \\
\hline Não & 1,00 & & 0,07 \\
\hline $\operatorname{Sim}$ & 0,47 & $0,21-1,07$ & \\
\hline \multicolumn{4}{|l|}{ Questionário CAGE * } \\
\hline Negativo & 1,00 & & 0,04 \\
\hline Positivo & 2,43 & $1,06-5,57$ & \\
\hline \multicolumn{4}{|l|}{ Hábito de escovar os dentes * } \\
\hline Em todas as refeições & 1,00 & & 0,8 ** \\
\hline Em alguma refeição & 1,04 & $0,79-1,40$ & \\
\hline Em algum dia da semana & 1,12 & $0,75-1,67$ & \\
\hline \multicolumn{4}{|l|}{ 3o nível } \\
\hline Tempo de diagnóstico (anos) * & 1,07 & $1,04-1,11$ & 0,001 \\
\hline \multicolumn{4}{|l|}{ Grupo de transmissão } \\
\hline Heterossexual/Transfusão & 1,00 & & $0,3 * \star \star$ \\
\hline Homo ou bissexual & 1,34 & $0,85-2,10$ & \\
\hline Uso de drogas injetáveis & 1,30 & $0,91-1,86$ & \\
\hline \multicolumn{4}{|l|}{ Uso de anti-retrovirais * } \\
\hline Não & 1,00 & & 0,06 \\
\hline Sim & 0,74 & $0,54-1,01$ & \\
\hline \multicolumn{4}{|l|}{ Internação * } \\
\hline Não & 1,00 & & 0,001 \\
\hline $\operatorname{Sim}$ & 1,79 & $1,38-2,34$ & \\
\hline
\end{tabular}

(continua) 
Tabela 3 (continuação)

\begin{tabular}{lccc}
\hline Níveis/Fatores & RP ajustada & IC95\% & Valor de $\mathbf{p}$ \\
\hline Carga viral no diagnóstico & 0,99 & $0,89-1,09$ & 0,84 \\
Linfócitos T CD4 no diagnóstico * & 0,999 & $0,99-0,99$ & 0,001 \\
Linfócitos T CD4 no exame * & 1,00 & $0,99-1,00$ & 0,5 \\
Carga viral no exame * & 1,12 & $1,05-1,21$ & 0,001 \\
\hline
\end{tabular}

1ㅡ nível ( $n=300$ ): variáveis sócio-demográficas (faixa etária, cor, sexo, estado civil, escolaridade e renda per capita familiar);

2o nível ( $n=300$ ): ajustado para o nível anterior e às variáveis hábitos e costumes (escovar os dentes, uso de fumo e álcool e questionário CAGE); $3^{\circ}$ nível $(n=298)$ : ajustado para os níveis anteriores e às variáveis clínicas e laboratoriais (forma de transmissão, tempo de HIV, carga viral e linfócitos T CD4 iniciais e no exame bucal, uso de anti-retrovirais e internação).

* Modelo final da regressão de Poisson;

** Teste de tendência linear;

$\star \star \star$ Teste de heterogeneidade.

\section{Discussão}

O estudo demonstrou que houve uma relação inversa do desfecho com o sexo feminino e com a contagem de linfócitos T CD4, no diagnóstico do HIV, e que houve maior risco entre aqueles pacientes com menor escolaridade, menor renda, maior consumo de cigarros, dependência ao álcool, maior tempo de infecção pelo HIV e carga viral mais elevada no momento do exame. Em relação a questões comportamentais, como o uso e dependência de álcool, tabagismo e higiene bucal, pode ter havido algumas subestimações porque os participantes podem informar negativamente esta condição por receio ou constrangimento. Se isso ocorreu, a RP estará subestimada. Por serem dados secundários, as medidas de carga viral e linfócitos T CD4 não necessariamente representam os valores na data do diagnóstico ou do exame realizado. Mesmo assim, como a variação máxima foi de aproximadamente três meses, e como os pacientes eram acompanhados regularmente com realização de exames, tais dados são bastante próximos ao momento do estudo.

A prevalência de $39 \%$ de lesões bucais nos pacientes estudados está próxima aos valores encontrados por outros estudos. Alguns estudos brasileiros indicam cifras que vão de $22 \%$ a $74 \%$ 2,4 , mostrando diferenças que podem acontecer em razão de aspectos metodológicos. Em estudos realizados fora do Brasil, têm sido encontrados valores que também variaram entre $49 \%$ e $66 \%$ 6,11,12,13. Além de questões metodológicas, as variações podem ter ocorrido também por diferenças nas políticas de ARV entre os países. A manifestação estomatológica mais prevalente foi a candidíase, com 59\%. Esta lesão tem sido amplamente associada à infecção pelo HIV e foi encontrada como lesão mais prevalente nos estudos realizados em adultos e crianças $2,6,11,13$, estando associada com baixa contagem de linfócitos $\mathrm{T}$ CD4, e com a evolução da imunossupressão 4 . A leucoplasia pilosa representa uma infecção oportunista relacionada ao vírus Epstein-Barr e se apresenta de modo especial nos pacientes infectados pelo HIV 5. Essa lesão atraiu a atenção precocemente na epidemia global da AIDS, considerando seu potencial como fator prognóstico de infecção por HIV 3 . Na atual pesquisa, 19,5\% dos pacientes apresentaram este tipo de lesão, dado próximo ao de outros trabalhos 2,5. Dentre os pacientes examinados, nenhum apresentou sarcoma de Kaposi. Essa lesão apresenta, ultimamente, baixa prevalência em alguns locais 10,14 . Caterino-de-Araujo et al. 14 analisaram uma possível relação entre o vírus do herpes tipo 8 (HHV-8) e sua associação aos fatores de risco e sarcoma de Kaposi. Os autores concluíram que, embora os anticorpos do HHV-8 tenham sido encontrados em mulheres HIV positivas, nenhum caso de sarcoma de Kaposi foi detectado e isso pode ter acontecido por causa de fatores de proteção contra sarcoma de Kaposi.

Entre os fatores sócio-econômicos, a renda familiar per capita demonstrou uma associação inversa em que os mais pobres desenvolvem mais este tipo de desfecho. Pessoas mais pobres e menos assistidas são mais vulneráveis a doenças infecciosas, por razões sociais e biológicas. Alguns fatores impedem medidas de contenção da infecção, tais como barreiras culturais, falta de recursos, menos escolaridade, desemprego, a fome e a desigualdade no acesso ao serviço de saúde 15 . Foi encontrada uma associação entre o desfecho e alguns hábitos. O consumo de bebida alcoólica teve um valor de p muito próximo do limite estabelecido ( $p=0,07)$. Entretanto, houve uma associação significativa entre o questionário CAGE e lesão bucal $(p=0,04)$. A explicação para esta relação seria o fato de que quem tem desor- 
dens por uso de álcool teria uma maior exposição aos efeitos do álcool, talvez pela maior quantidade ingerida e, além disso, poderia haver mais fatores deletérios, como baixa adesão aos ARV e menor higiene bucal. Outro fator relacionado é o hábito do tabagismo, sendo observada uma relação de tipo dose-resposta em que, para cada cigarro a mais fumado, o risco aumentou em $2 \%$. Outros autores também encontraram associação entre lesões bucais e tabagismo ${ }^{5}$. Os efeitos carcinogênicos do tabaco associam-se a produtos de sua metabolização como, por exemplo, nitrosaminas 16 . A adesão da cândida na mucosa bucal é fundamental para o processo de candidíase, e o fumo pode facilitar esta adesão. Enzimas salivares, imunoglobulinas, linfócitos polimorfonucleares e a flora normal bacteriana são importantes para inibir a colonização da cândida na mucosa bucal ${ }^{17}$. Assim, pode-se supor que substâncias do tabaco interfiram no mecanismo de proteção do epitélio da mucosa bucal pelos danos teciduais locais ou genéticos, além de agir sobre glândulas salivares e mucosas. Isso levaria a uma destruição desses mecanismos, com conseqüente exposição do epitélio, criando uma porta de entrada para microorganismos e facilitando a adesão e proliferação desses diversos agentes nessa superfície.

A relação entre a diminuição da probabilidade de lesão bucal com valores elevados de linfócitos T CD4 e reduzidos de carga viral encontrada no presente estudo se verifica também em outras pesquisas 5,10 . A literatura confirma que a alteração no nível de linfócitos T CD4 é inversamente proporcional à freqüência de aparecimento das manifestações bucais, e o aparecimento de cândida e de outras lesões está relacionado ao diagnóstico de AIDS 1,4. Ainda que alguns pesquisadores tenham observado uma redução acentuada na ocorrência de infecções oportunistas com a TARV 7,9,10, no presente estudo esse efeito teve um valor de $\mathrm{p}$ não significante. Isto pode explicar-se pelo fato de a maioria dos pacientes classificados como "sem uso de ARV" não terem indicação de TARV, estando em situação imunológica melhor.

Algumas considerações devem fazer parte da pesquisa, dentre elas, as limitações apresentadas pelo estudo transversal. Com ele, não se pode confirmar associação causal com o desfecho. Além disso, a validade externa fica limitada, dado que a amostra foi selecionada, acompanhada em ambulatório, ou seja, amostra de serviço de saúde não permite que os dados sejam inferidos para a população.

Os resultados do presente estudo confirmam uma alta prevalência de lesões bucais e apontam para uma maior valorização do exame da cavidade bucal, em função de seu fácil acesso e grande importância clínica. Deve ser realizado em todos os pacientes HIV positivos ou com suspeita, visto ser um achado clínico de utilidade, revelando uma redução da imunidade e advertindo para demais manifestações oportunistas. A associação significativa com fatores demográficos, sócio-econômicos e uso de álcool e fumo, evidencia a importante carga social vinculada a este problema, assim como sua relação com determinados hábitos e costumes, que podem ser modificados.

\section{Resumo}

O objetivo deste estudo foi avaliar a prevalência de lesões bucais entre pacientes HIV positivos e identificar fatores associados a tais lesões. Foi realizado estudo transversal que coletou dados mediante entrevista, exame clínico e consulta aos prontuários médicos de pacientes adultos atendidos no Serviço de HIV-AIDS do Hospital Universitário da Universidade Federal do Rio Grande, Rio Grande do Sul, Brasil, sendo considerados fatores sócio-demográficos, imunológicos e terapêuticos. Foi utilizada a regressão de Poisson num modelo hierárquico de análise. Entre abril de 2006 a janeiro de 2007 foram observados 300 pacientes, sendo $51 \%$ do sexo masculino e média de idade de 40 anos: $39 \%$ apresentaram lesões bucais, sendo a candidíase a mais freqüente (59,1\%), seguida de leucoplasia pilosa $(19,5 \%)$. As mulheres apresentaram um risco menor, com observância de uma associação inversa com o CD4. Houve um risco maior entre aqueles pacientes com menor escolaridade, menor renda, tabagistas, dependentes do álcool, com maior tempo de infecção pelo $H I V$ e carga viral mais elevada. Os dados confirmaram a elevada prevalência das manifestações bucais oportunistas e evidenciaram a sua relação com a situação social, assim como sua relação com determinados hábitos e costumes passíveis de modificação.

Manifestações Bucais; Saúde Bucal; HIV 


\section{Colaboradores}

A. B. Gasparin e F. V. Ferreira participaram da concepção do projeto, do planejamento, da execução, da análise e da redação do artigo. C. C. Danesi, e J. Silveira contribuíram na concepção do projeto, no planejamento, na metodologia e na redação do artigo. R. A. Mendoza-Sassi colaborou na concepção do projeto, no planejamento, na análise e na redação do artigo. A. M. B. Martinez, L. Zhang e J. A. Cesar participaram da redação final do artigo.

\section{Referências}

1. Aguirre-Urízar JM, Echebarría-Goicouría MA, Eguía-Del Valle A. Síndrome de inmunodeficiencia adquirida: manifestaciones en la cavidad bucal. Med Oral Patol Oral Cir Bucal 2004; 9 Suppl: S148-57.

2. Cavassani VGS, Andrade Sobrinho J, Homem MGN, Rapoport A. Candidíase oral como marcador de prognóstico em pacientes portadores do HIV. Rev Bras Otorrinolaringol 2002; 68:630-4.

3. Robinson PG. The oral manifestations of HIV infection. Int J STD AIDS 1997; 8:668-74.

4. Miziara ID, Lima AS, Cataldo RA. Oral candidiasis and hairy leukoplakia as progression markers of HIV infection in Brazilian patients. Rev Bras Otorrinolaringol 2004; 70:310-4.

5. Patton LL, McKaig RG, Eron Jr. J, Lawrence HP, Strauss RP. Oral hairy leukoplakia and oral candidosis as predictors of HIV viral load. AIDS 1999; 13:2174-6.

6. Vilma T, Guerra M, Bravo-Sosa IM, Albornoz E, Lambertini A, Ibarra G. Manifestaciones bucales e infecciones oportunistas mas frecuentes encontradas en 208 pacientes con infección por VIH/SIDA. Acta Odontol Venez 2002; 40:260-4.

7. Hodgson TA, Greenspan D, Greenspan JS. Oral lesions of HIV disease and HAART in industrialized countries. Adv Dent Res 2006; 19:57-62.

8. Patton LL, McKaig R, Strauss R, Rogers D, Eron Jr. J. Changing prevalence of oral manifestations of human immuno-deficiency virus in the era of protease inhibitor therapy. Oral Surg Oral Med Oral Pathol Oral Radiol Endod 2000; 89:299-304.

9. Ministério da Saúde. Recomendações para terapia anti-retroviral em adultos e adolescentes infectados pelo HIV. Brasília: Ministério da Saúde; 2006.

\section{Agradecimentos}

Ao Conselho Nacional de Desenvolvimento Científico e Tecnológico (CNPq) pela bolsa de iniciação científica, processo $\mathrm{n}^{\circ}$. 110966/2005-0.
10. Nicolatou-Galitis O, Velegraki A, Paikos S, Economopoulou P, Stefaniotis T, Papanikolaou IS, et al. Effect of PI-HAART on the prevalence of oral lesions in HIV-1 infected patients. A Greek study. Oral Dis 2004; 10:145-50.

11. Khongkunthian P, Grote M, Isaratanan W, Piyaworawong S, Reichart PA. Oral manifestations in 45 HIV-positive children from Northern Thailand. J Oral Pathol Med 2001; 309:549-52.

12. Ramírez-Amador V, Esquivel-Pedraza L, IrigoyenCamacho E, Anaya-Saavedra G, González-Ramírez I. Asociación de lesiones bucales con el estado serológico para el VIH. Salud Pública Méx 2002; 44:87-91.

13. Flaitz C, Wullbrandt B, Sexton J, Bourdon T, Hicks J. Prevalence of orodental findings in HIV-infected Romanian children. Pediatr Dent 2001; 23:44-50.

14. Caterino-de-Araujo A, Santos-Fortuna EL, Carbone PHL, Cibella SEL, Moreira AA. Human herpesvirus-8 (HHV-8) antibodies in women from São Paulo, Brazil: association with behavioral factors and Kaposi's sarcoma. Braz J Infect Dis 2003; 76:395-401.

15. Bastos FI, Szwarcwald CL. AIDS e pauperização: principais conceitos e evidências empíricas. Cad Saúde Pública 2000; 16 Suppl 1:S65-76.

16. Prado RF, Taveira LAA. Nicotina na carcinogênese química bucal. Rev Bras Patol Oral 2003; 4:24-7.

17. Samaranayake LP, Fidel PL, Naglik JR, Sweet SP, Teanpaisan R, Coogan MM, et al. Fungal infections associated with HIV infection. Oral Dis 2002; 8:151-60.

Recebido em 04/Jun/2008

Versão final recebida em 22/Dez/2008

Aprovado em 03/Fev/2009 